\title{
Typology of Non-Wood Forest Products Based Enterprises in Serbia
}

\author{
Dragan NONIĆ ${ }^{*}$, Mersudin AVDIBEGOVIĆ 2 , Jelena NEDELJKOVIĆ ${ }^{1}$, \\ Nenad RANKOVIĆ ${ }^{1}$, Viorel MARINESCU ${ }^{3}$, Florin IORAS ${ }^{4}$ \\ ${ }^{1}$ University of Belgrade, Faculty of Forestry, 1 Kneza Višeslava St., Belgrade, Serbia; dragan.nonic@sfb.bg.ac.rs (" corresponding author), \\ jelena.nedeljkovic@sfb.bg.ac.rs,nenad.rankovic@sfb.bg.ac.rs \\ ${ }^{2}$ University of Sarajevo, Faculty of Forestry, 20 Zagrebačka St., Sarajevo, Bosnia-Herzegovina; mavdibegovic@gmail.com \\ ${ }^{3}$ Transilvania University of Brasov, Faculty of Silviculture and Forest Engineering, 1 Sirul Beethoven, Brasov, Romania; marinescuviorel@gmail.com \\ ${ }^{4}$ Buckinghamshire New University, Queen Alexandra Rd, High Wycombe, Buckinghamshire HP11 2JZ, United Kingdom; florin.ioras@gmail.com
}

\begin{abstract}
In Serbia, as in other European countries, small and medium enterprises are recognized as a pillar of economic development. At the same time, a clear need for support to those enterprises and entrepreneurship, both in urban and rural areas, is emphasized in national strategic documents. In forestry, small and medium enterprises are of special importance for sector development. However, in Serbia, there is a lack of knowledge about them, and particularly about small and medium enterprises whose business is based on non-wood forest products. Bearing in mind the importance of these enterprises for development of private forestry sector and rural areas, research aiming to determine their characteristics and types is needed. Door-to-door survey was conducted with 91 representatives of non-wood forest products based small and medium enterprises in Central Serbia. Results of cluster analysis showed there were three types of non-wood forest products based small and medium enterprises, in regard to their characteristics. The same number of types was distinguished, in regard to business activities. Results of this research can be used for further detailed study on types of forest-based small and medium enterprises and as a basis for formulation of support measures and, thus, improvement of the entrepreneurship in non-wood forest products sector in Serbia.
\end{abstract}

Keywords: Central Serbia, forest products, private sector, small and medium enterprises, type of enterprise

\section{Introduction}

Small and medium enterprises (SMEs) contribute to overall economy through income, regional development, employment (social contribution), share in GDP, innovations etc. Therefore, the knowledge regarding the factors which affect this sector and its characteristics is important, both for countries with developed market economies and for those with economies in transition.

This is corroborated in the UNECE report, which states that "...the core of the political and economic transformation of any country in transition is the creation of the private sector, the development of entrepreneurship and creation of small and medium-sized enterprises. They are considered to be one of the principal driving forces in economic development" (UNECE, 2003). SMEs have a positive impact on the development of private ownership, entrepreneurial skills, job creation and diversification of economic activities, and can quickly adapt to market changes, contributing significantly to the trade and export (UNECE, 2003). When it comes to forestry, the situation is more complex, because it is a very specific area of the country's economy. In that sense, as forestry in Serbia is also in process of transition, with all sectors' characteristics, it is important to know the mechanisms and factors which influence the formation and development of SMEs in forestry sector.

The contribution of the forestry sector to the economic and social development can be increased by providing necessary support for the establishment and development of SMEs that base their business on forests (Ranković et al., 2012). To properly plan the development of the private forestry sector and ensure the development of SMEs in forestry, it is necessary, in addition to wood products, to pay special attention to non-wood forest products ${ }^{1}$ (NWFPs).

Previous research shows that entrepreneurs in forestry sector should take into account NWFPs, when exploring new development strategies, as these products provide significant opportunities for additional revenues (Niskanen et al., 2007). In this paper, mushrooms, medicinal and aromatic plants (MAP), wild berries and other forest fruits (WBFF) are considered as NWFPs.

\footnotetext{
${ }^{1}$ NWFPs are "...goods of biological origin other than wood, derived from forests, other wooded land and trees outside forests" (FAO, 1999).
} 
In literature regarding SMEs for the procurement, processing and selling of NWFPs (NWFP-SMEs) is stated that the organization of these enterprises in Serbia is very heterogeneous, and production capacities are underutilized and often inadequate. One of the reasons for this may be the lack of adequate support, as it was identified that most of these enterprises do not have sufficient financial resources, nor do they have access to favourable bank loans (Nonić et al., 2013a).

In many countries, there is a noticeable lack of support for development of SMEs in forestry and, if support exists, it is often inadequate or poorly targeted (Ioras et al., 2001; Macqueen, 2007; Stancioiu et al., 2010; Abrudan, 2012). Therefore, policy-makers may need "...policies that support the varying needs of different types of entrepreneur, rather than provide broad 'blanket' policies to all types of entrepreneur, irrespective of need or ability" (Westhead $e t$ al., 2005). For these reasons, it is essential that decisionmakers have the necessary information about the types of enterprises in the private forestry sector, or in this case, NWFP-SMEs.

Several typologies of SMEs (Andersen, 2012; Franco and Haase, 2013; Swoboda and Olejnik, 2013) and entrepreneurs are described (Dowell et al., 2012; Westhead et al., 2005). Also, some authors have studied the types of business strategies, which are not strictly focussing on SMEs, but can be applied to them (Miller and Roth, 1994).

In the private forestry sector in Serbia, previous studies have identified several types of classification, in relation to private forest owners (Nonić et al., 2013a); SMEs and entrepreneurs operating with wood products (Ranković $e t$ al., 2012); supply chains of NWFPs (Nonić et al., 2013b), and the attitudes of representatives of NWFP-SMEs towards the documentation needed for NWFPs collection (Nedeljković et al., 2013).

Despite these previous studies, in Serbia remains a lack of knowledge about the types of NWFP-SMEs. For this reason, the aim of this research was to assess the characteristics and types of NWFP-SMEs in Central $\mathrm{Serbia}^{2}$. An important purpose of the research is to create a basis for further research and improvement of the entrepreneurship in NWFP sector.

\section{Methodology}

In this study, the quantitative research approach was applied. "Door-to-door" survey (Malhotra, 2007) was used as a research technique for data collection. The questionnaire was a combination of 65 questions (open- and close-ended), divided into six groups. For the purpose of this paper only questions related to the basic characteristics of NWFP-SMEs and their business were selected.
During the statistical processing (in SPSS, ver. 20), in the case of continuous variables, descriptive statistics was used, while in the case of category variables, frequency analysis was applied. Cluster analysis was also employed as it is frequently applied for assessing the specific typology in socio-economic studies (Swoboda and Olejnik, 2013).

Two-step cluster analysis (Malhotra, 2007) was applied for grouping objects into relatively homogeneous groups (so-called clusters), i.e. to determine the type of SMEs. The criterion for clustering was Schwarz's Bayesian Criterion (BIC). Two-step cluster analysis allows grouping of only categorical, and both categorical and non-categorical variables, and does not require prior knowledge on number and characteristics of clusters. Those are determined by the value of BIC and Ratio of Distance Measures (RDM). The quality of the grouping is determined on the basis of Silhouette coefficient ${ }^{3}$. To test the differences in the obtained (empiric) and expected frequencies ${ }^{4}$, $\chi 2$ test for goodness-of-fit was used.

Basic information (name, registered office, contact) on NWFP-SMEs, were obtained from internal reports of the Ministry of Environment, Mining and Spatial Plannings,

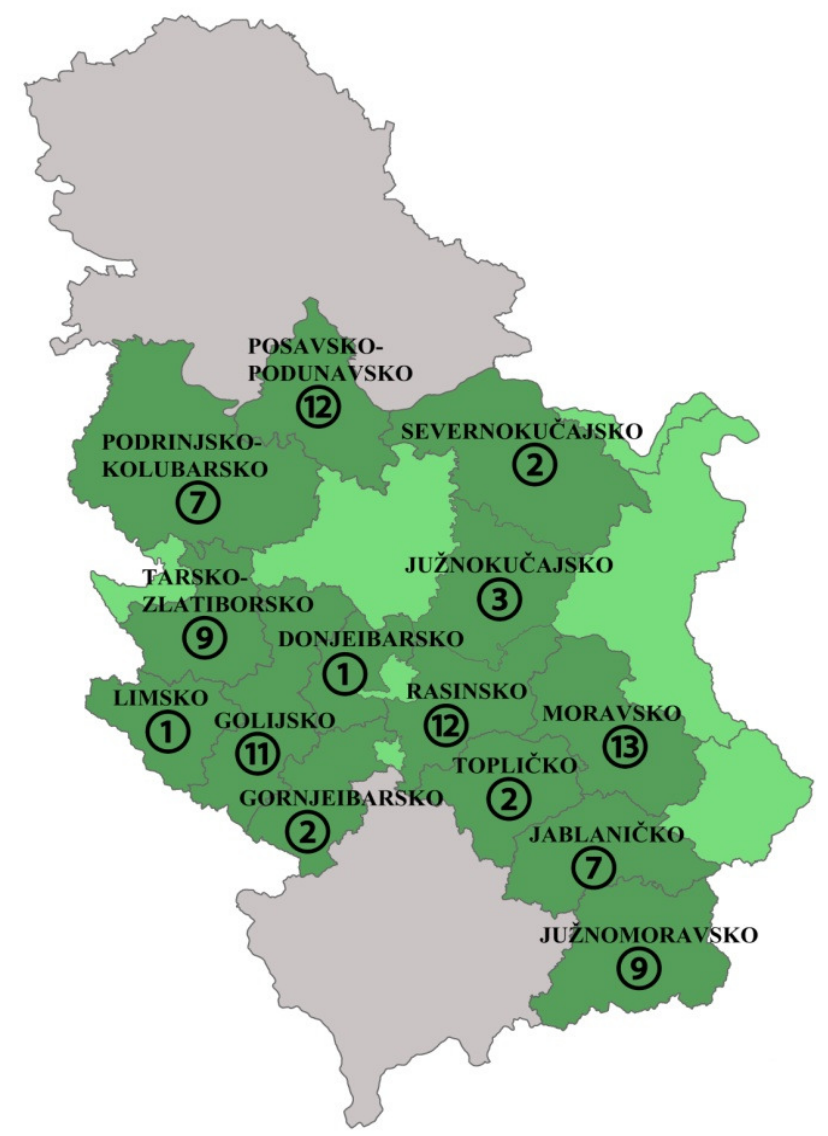

Fig. 1. Territorial distribution of surveyed NWFP-SMEs

\footnotetext{
${ }^{2}$ Term "Central Serbia" refers to the territory of Serbia without AP Vojvodina, and Kosovo and Metohija.

${ }^{3}$ If the average value of Silhouette is $0.70-1$, quality of data grouping is strong, if $>0.50$ and $\leq 0.70$, quality is reasonable, if $>0.25$ and $\leq 0.50$, quality is week, and if $\leq 0.25$, grouping is not statistically significant (Pearson et al., 2004).

${ }^{4}$ In all cases it was assumed that expected (hypothetical) frequency distribution was $50 \%: 50 \%$, i.e. null hypothesis was that all proportions were equal.

${ }^{5}$ In accordance to the Decree on putting under control the use and trade of wild flora and fauna, all legal entities, engaged in collection of NWFPs for commercial purposes, are obliged to have the permit. A national register of these legal entities is kept, based on the data from the permits.
} 
$70 \%$

$60 \%$

$50 \%$

$40 \%$

$30 \%$

$20 \%$

$10 \%$

$0 \%$

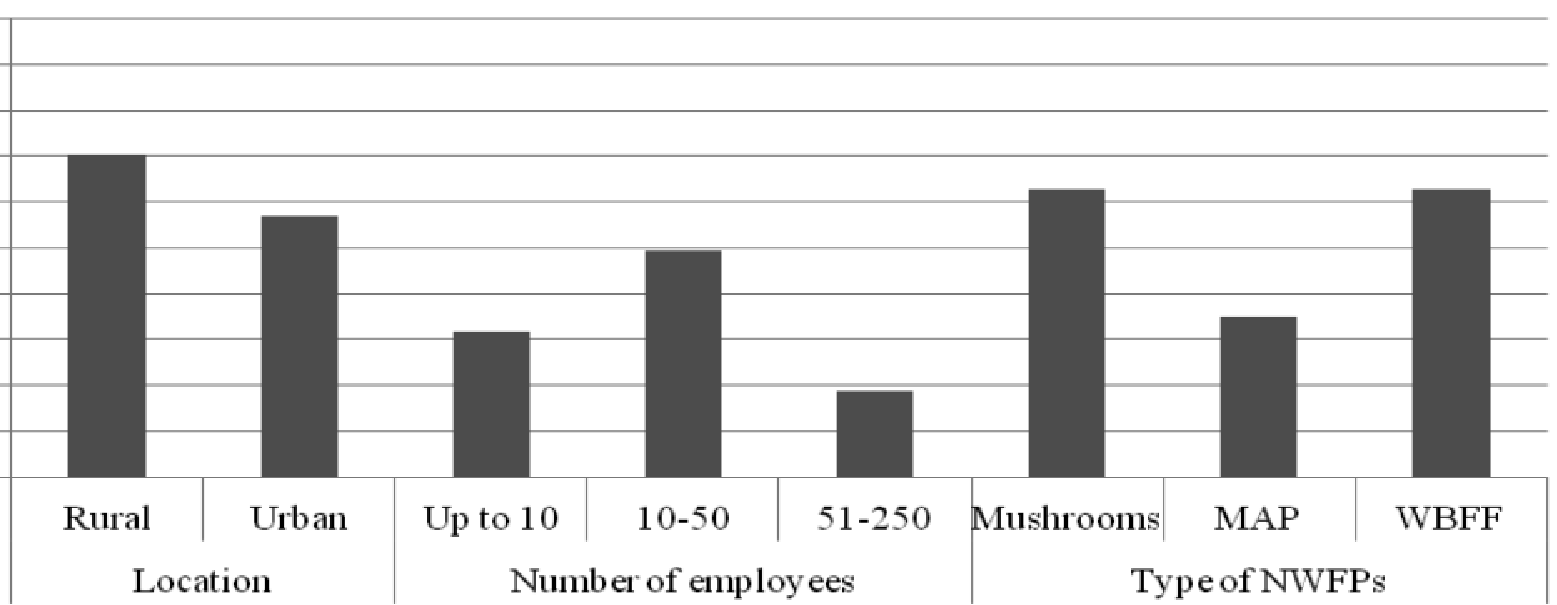

Fig. 2. Basic characteristics of NWFP-SMEs

which was, at the time of data collection, responsible for these tasks. After receiving basic information on those enterprises, the first step was to determine the final number of SMEs, which requested permit for the collection and marketing of protected species in the period 2007-2010. Next step included liquidity checking. The data on the liquidity of NWFPs based enterprises were obtained through telephone contact with SMEs, whose contact details were available in internal reports of the Ministry, as well as through checking the database of Serbian Business Register Agency and the National Bank of Serbia. On such basis the final number of active SMEs was defined.

Data collection was undertaken in the period AugustNovember 2011 based on discussions with the representatives of 91 enterprises (from a total number of 127 SMEs active at the time of investigation).

Distribution of NWFP-SMEs in selected forest areas in Central Serbia is shown in Fig. 1. Because the population was relatively small, sampling was not used in the research, i.e. a census was conducted (Malhotra, 2007).

\section{Results}

Basic characteristics of NWFP-SME $s$ considered in this research are shown in Fig. 2. In relation to the location, the NWFP-SMEs are mainly located in rural area, $27.4 \%$ of the companies being active in both rural and urban areas.

Around half of the NWFP-SMEs (49.5\%) have 11-50 employees. Results of $\chi^{2}$ test for goodness-of-fit show statistically significant difference between the company size groups $(\chi 2=13.01, \mathrm{df}=2, \mathrm{p}=0.001)$. Most enterprises, in regard to the number of employees, belong to the group of small enterprises.

Most of the investigated NWFP-SMEs (84.6\%) hire seasonal workers, whose average number is 10 and maximal 250. NWFP-SMEs need to hire seasonal workers because of the collection period, as purchase and processing of NWFPs are seasonal activities, preformed mainly during the summer and autumn seasons. Regarding the type of NWFPs, most SMEs (62.2\%) are engaged in mushrooms and WBFF business, and $35.2 \%$ in MAP.

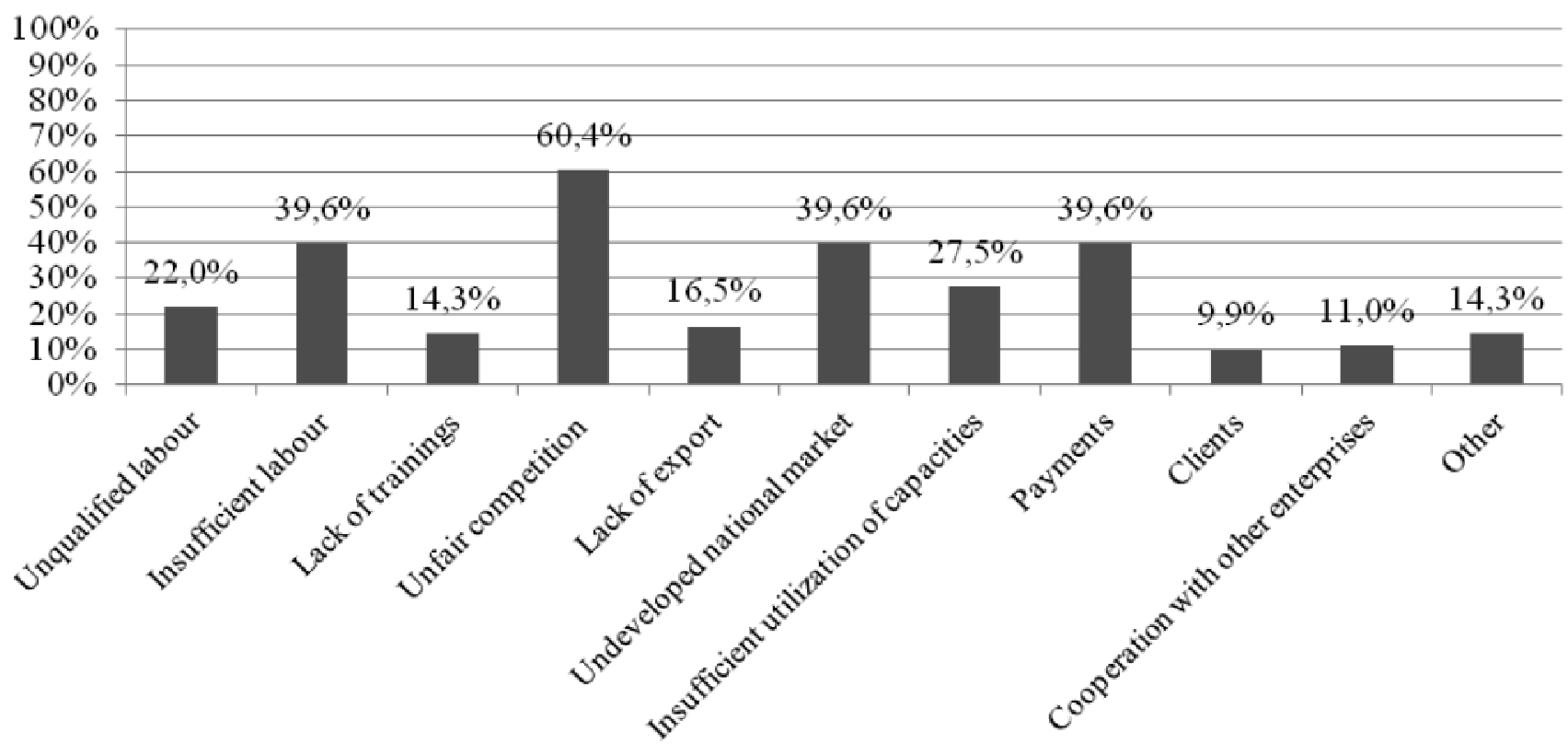

Fig. 3. Main problems in NWFPs business 
Tab. 1. Enterprise types based on their characteristics

\begin{tabular}{lcccc}
\hline $\begin{array}{c}\text { Type of } \\
\text { enterprise }\end{array}$ & Frequency & Location & $\begin{array}{c}\text { Number of } \\
\text { employees }\end{array}$ & $\begin{array}{c}\text { Number of seasonal } \\
\text { workers }\end{array}$ \\
\hline Small rural & $47.3 \%$ & Rural & $11-50$ & 14 \\
Small urban & $34.1 \%$ & Urban & $11-50$ & 13 \\
Medium & $18.6 \%$ & Urban and rural & $51-250$ & 118 \\
\hline
\end{tabular}

Business activities of most NWFP-SMEs include procurement (98.9\%), processing (95.6\%) and selling (69.2\%). Also, NWFP-related business activities are the main or sole activity for $73.6 \%$ of SMEs.

Respondents believe that working conditions are mostly determined by weather (78.7\%), which is understandable bearing in mind that NWFPs yield depends mainly on nature and weather conditions. In addition, the majority of respondents (70.8\%) claim that legal framework is inadequate. Only $14.6 \%$ stated that working conditions are influenced by the old equipment and mechanization process.

Fig. 3 presents the attitudes of respondents towards the main problems they face in NWFPs business.

Unfair competition seems to be the most important problem in this business, according to $60.4 \%$ of SMEs representatives. They also reveal that insufficient labour, undeveloped national market, and payments are relevant impediments in business development. On the other hand, a small number of respondents indicated some problems caused by clients (9.9\%) and cooperation with other enterprises $(11.0 \%)$.

Three types of NWFP-SMEs were distinguished based on their characteristics (Tab. 1).

The prevailing type of NWFP-SMEs is "small rural enterprises", which is understandable, bearing in mind that the activities related to NWFPs, particularly procurement of raw materials, take place in rural areas. This is because NWFPs collection and purchase are performed in villages and their surroundings, which are closer to the forest resources than urban areas. Results of $\chi 2$ test for goodness-offit show a statistically significant difference between these types $(\chi 2=11.16, \mathrm{df}=2, \mathrm{p}=0.004)$.

The only difference between "small rural" and "small urban" types is their location (very similar other characteristics). The "medium" type is significantly different from the other types, both in terms of the number of employees and seasonal workers.

Following types of enterprises were identified, based on their business activities:

-SMEs engaged in procurement, processing and selling of NWFPs (64.8\%);

-SMEs engaged in procurement and processing of NWFPs $(30.8 \%) ;$ (4.4\%).

-SMEs engaged in procurement and selling of NWFPs

Results of $\chi 2$ test for goodness-of-fit show a statistically significant difference between these types $(\chi 2=50.13, \mathrm{df}=2$, $\mathrm{p}=0.001)$. The prevailing type are enterprises, which are engaged in all three activities. This is understandable if one takes into account the above results, which indicate that procurement and processing are present in almost all studied SMEs and selling in the majority.

\section{Discussion}

The basic characteristics of analysed NWFP-SMEs (location mainly in rural areas but also in urban areas, small enterprises, the most common NWFPs are mushrooms and WBFF) are in accordance with previous studies, which suggest that forest-based enterprises (especially those engaged in NWFP-based activities) are mainly small family enterprises (FAO, 2005), located in rural areas (Niskanen et al., 2007; Pettenella et al., 2007). The majority of the analysed enterprises belongs to the type "small rural". This way, the development of local economies and preservation of ecosystems and biodiversity of rural areas are encouraged (Nedeljković et al., 2012).

Selling is performed by most enterprises, while almost all of them are engaged in procurement and processing. The prevailing type of NWFP-SMEs, distinguished on the basis of their activities, is the one that integrates procurement, processing and selling. Previous studies in the region of Sumadija and Western Serbia showed similar results. This can be assessed as a positive feature, because it helps to ensure a smooth flow of information, knowledge and experience, which is one of the bases for an effective functioning of the entire sector (Nonić et al., 2013b).

Research results show that weather significantly influences working conditions. Considering that NWFPs are seasonal products, whose yield depend on nature and weather "...their supply cannot be regular and fully reliable" (FAO, 2005). This is the reason why SMEs in this sector "...seldom rely on one product" (FAO, 2005). In this way, they are trying to minimize potential losses.

The most important impediments in this business are unfair competition, insufficient labour, underdevelopment of national market, and cash flow. Although there are certain differences in attitudes, these problems are to some extent similar to those reported in the literature. Research conducted in other countries shows that the main problems are: "...lack of capital investment and shortage of raw materials, skilled manpower and up-to-date information" (Uddin et al., 2008). Also, other impediments in the development of the business are "...financial and technical limitations, market insecurity (with large price fluctuations) and lack of research" (Uddin et al., 2008).

\section{Conclusion}

Findings of this research demonstrate that the majority of the enterprises, according to the number of employees, belong to the group of small enterprises (11-50 employees). Most of them are engaged in all three activities (procurement, processing, selling), with NWFPs being the predominant/sole activity. Working conditions are 
587

influenced by weather and inadequate legal framework, while the most important problem in business development is "unfair competition". Research results showed three types of NWFP-SMEs, in regard to basic characteristics of SMEs ("small rural" is prevailing), and three types in regard to business activities ("procurement, processing, selling" is prevailing). These results are of importance for rural areas, since entrepreneurship based on NWFPs can have a positive impact on the sustainable development of rural areas and the population income diversification.

Future research should be focused on the specific support measures in relation to different types of NWFPSMEs. Results of this research can be used for further detailed study on the different types of forest-based SMEs and as a basis for formulation of subsidies/support measures in order to improve the entrepreneurship in NWFPs sector of Serbia.

\section{Acknowledgments}

This research was conducted in the frame of the project "Research on climate changes and its impact on the environment - monitoring of impacts, adaptation and mitigation" (no. 43007), subproject "Socio-economic development, mitigation and adaptation to climate changes" (no. 43007/16-III), funded by the Ministry of Education, Science and Technological Development.

\section{References}

Abrudan IV (2012). A decade of non-state forest administration in Romania: achievements and challenges. International Forestry Review 14(3):275-284

Andersén J (2012). A resource-based taxonomy of manufacturing MSMEs. International Journal of Entrepreneurial Behaviour \& Research 18(1):98-122.

Dowell D, Dawson C, Fuller-Love N, Hopkins B (2012). Entrepreneurial groups in Ireland and Wales: A preliminary typology of entrepreneurs using a marketing segmentation approach. Journal of Research in Marketing and Entrepreneurship 14(2):184-198.

FAO (2005). Microfinance and forest-based small-scale enterprises. FAO Forestry Paper 146, Rome.

FAO (1999). Towards a harmonized definition of non-wood forest product. Unasylva 198(50):63-64.

Franco M, Haase H (2013). Interfirm Alliances: A Taxonomy for SMEs. Long Range Plann. Advance online publication doi:10.1016/j.lrp.2013.08.007.

Ioraş F, Muica N, Turnock D (2001). Approaches to sustainable forestry in the Piatra Craiului National Park. GeoJournal 55(2-4):579-598.

Macqueen D (2007). The role of small and medium forest enterprise associations in reducing poverty. IIED, London.

Malhotra N (2007). Marketing research - an applied orientation, 5th Ed. Pearson Prentice Hall, Upper Saddle River, 811 p.

Miller JG, Roth AV (1994). A Taxonomy of Manufacturing Strategies. Manage Sci 40(3):285-304.
Nedeljković J, Nonić D, Ranković N, Mandić V (2012). Nonwood Forest Products-Based Enterprises in Western Serbia: Organisation of External Supply Chain. In: Rakonjac Lj. (ed.), CD ROM Proceedings from International Scientific Conference "Forests in Future - Sustainable Use, Risks and Challenges". Institute of Forestry:831-840.

Nedeljković J, Lovrić M, Nonić D, Stojanovska M, Nedanovska V, Lovrić N, Stojanovski V (2013). Influence of policy instruments on non-wood forest products commercialization in Croatia, Macedonia and Serbia. Šumarski list 9-10:473-486.

Niskanen A, Slee B, Ollonqvist P, Pettenella D, Bouriaud L, Rametsteiner E (2007). Entrepreneurship in the forest sector in Europe. Silva Carelica 52. University of Joensuu, Faculty of Forestry, Joensuu.

Nonić D, Ranković N, Glavonjić P, Nedeljković J (2013a). Typology of private forest owners in Serbia. Šumarstvo 34:133-156

Nonić D, Ranković N, Nedeljković J (2013b). Typology of the supply chains of non-wood forest products in Central Serbia. Glasnik Šumarskog fakulteta 108:145-168

Pearson RK, Zylkin T, Schwaber J, Gonye GE (2004). Quantitative evaluation of clustering results using computational negative controls. In: Berry M. (ed.), Proceedings of the Fourth SIAM International Conference on Data Mining, SIAM:188-199.

Pettenella D, Secco L, Maso D (2007). NWFP\&S Marketing: Lessons Learned and New Development Paths from Case Studies in Some European Countries. Small-scale Forestry 6(4):373-390.

Ranković N, Nonić D, Nedeljković J, Marinković M, Glavonjić P (2012). Small and medium enterprises in Timok forest area system of support measures and model of organization. Univerzitet Beogradu-Šumarski fakultet, Beograd.

Stancioiu PT, Abrudan IV, Dutca I (2010). The Natura 2000 ecological network and forests in Romania: implications on management and administration. International Forestry Review 12(1):106-113.

Swoboda B, Olejnik E (2013). A taxonomy of small- and mediumsized international family firms. J Int Entrep 11(2):130-157.

Uddin MS, Mukul SA, Khan MASA, Alamgir M, Harun MdY, Ala MS (2008). Small-scale Agar (Aquilaria agallocha Roxb.) Based Cottage Enterprises in Maulvibazar District of Bangladesh: Production, Marketing and Potential Contribution to Rural Development. Small-scale Forestry 7(2):139-149.

UNECE (2003). Small and medium enterprises in countries in transition. UNECE Series: Entrepreneurship and SMEs. ECE/TRADE/337 OPA/AC.32/1. UN, Geneva.

Westhead P, Ucbasaran D, Wright M, Binks M (2005). Novice, Serial and Portfolio Entrepreneur Behaviour and Contributions. Small Bus Econ 25(2):109-132. 